\title{
Elaboração do jogo "MyBio Game": uma ferramenta para o ensino interativo da biossegurança na área de análises clínicas
}

\author{
Game development "MyBio Game": an interactive teaching tool for \\ biosecurity in the clinical analysis field
}

\author{
1 Camila Panêto Rosa camila cpr@yahoo.com.br \\ 2 Carlos Alberto Sanches Pereira \\ 2 Paulo Roberto de Amoretty \\ 2 Gabriela Girão de Albuquerque
}

1 Discente do Centro Universitário de Volta Redonda, UniFOA.

2 Docente do Centro Universitário de Volta Redonda, UniFOA.

\section{RESUMO}

A biossegurança é o conjunto de estudos e ações que visam prevenir os acidentes no meio biotecnológico, ou seja, trata-se da conscientização dos profissionais da área aos possíveis riscos. Prevenir acidentes decorrentes dessa exposição é um dos principais interesses a serem sanados, devido ao fato de que muitos acidentes poderiam ser evitados, se houvesse um melhor sistema de educação relacionado às seguranças pessoal e do ambiente. Nota-se, atualmente, a necessidade de metodologias de ensino que sejam estimulantes e se adequem à modernidade do século em que vivemos. Por isso, as táticas de ensino estão passando por diversas mudanças, sendo usadas metodologias que prezem por incentivar a autoaprendizagem por meios interativos que estimulem o conhecimento, o senso crítico, entre outros. Um exemplo são os jogos didáticos que estão sendo cada vez mais introduzidos nas escolas, sendo bastante enriquecedores para o ensino lúdico e o aprendizado, com vantagens significativas, quando utilizados de forma a possibilitar a criação de suposições e habilidades práticas. Em virtude disso, foi proposta, como objetivo deste trabalho, a elaboração de um jogo relacionado à biossegurança, como método interativo de envolver o profissional ou futuros profissionais, visando minimizar os riscos de acidentes de trabalho. Pela nova metodologia de ensino, denominada mobile learning, utilizada por consequência à fácil acessibilidade, que permite o ensino a distância e que, além de oferecer o aprendizado, é dinâmica, interativa e funcional na comunicação móvel. Nessa perspectiva, compreende-se que a educação é primordial para a vida pessoal e profissional de um indivíduo e afeta diretamente o nível de segurança que ele terá no seu ambiente de trabalho, principalmente para o profissional que atua na área Biotecnológica, havendo assim, a necessidade de um meio interativo de transmissão das regras básicas de segurança nessa área, de forma que elas sejam internalizadas e colocadas em prática.

\section{Palavras-chave}

Mobile learning; ensino; biossegurança.

\begin{abstract}
Biosecurity is the set of studies and actions aimed at preventing accidents among biotechnology, ie, it is of the professionals aware of the possible risks. Prevent accidents resulting from such exposure is one of the main interests to be solved due to the fact that many accidents could be avoided if there were a better education system related to personal and environmental safety. Currently it is noted the need for teaching methods that are stimulating and suited the modern century we live in, so the teaching tactics are going through many changes, being used methodologies prezem to stimulate self-learning through interactive media that encourage knowledge, critical thinking, among others. An example of them are the educational games that are being increasingly introduced into schools, they are very enriching for the playful teaching and learning, with significant advantages when used, enabling the creation of assumptions and practical skills. Because it has been proposed as objective the development of a related game biosafety as interactive method to involve professional, or future professionals to minimize the risks of accidents, the new methodology called mobile learning teaching methodology accordingly the easy accessibility that enables distance learning and in addition to offering learning is dynamic, interactive and functional in mobile communication. It is understood that education is essential for personal and professional life of an individual and directly affects the level of security that it will have on your desktop, especially for professional engaged in the Biotechnology area, having thus, the need for an interactive means for transmitting the basic safety rules in this area, so that they are internalized and put into practice.
\end{abstract}

\section{Keywords}

Mobile learning; education; biosecurity.

\section{Como você deve citar?}

ROSA, Camila Panêto et al. Elaboração do jogo "MyBio Game": uma ferramenta para o ensino interativo da biossegurança na área de análises clínicas. Cadernos UniFOA, Volta Redonda, n. 32, p. 97-108, dez. 2016. 


\section{INTRODUÇÃO}

A biossegurança é um conjunto de ações que tem como fundamento básico garantir o avanço tecnológico, minimizar ou eliminar os riscos inerentes ao trabalho, assim como a proteção da saúde animal e humana e o meio ambiente (CTNBio, 2001).

A preocupação com a segurança do profissional, especialmente de profissionais que trabalham na área da saúde, vem aumentando em grande escala nos últimos anos. Devido a isso, novos métodos e normas têm sido elaborados para uma melhor garantia de vida dos trabalhadores que se expõem aos agentes de riscos (SILVA; MASTROENI, 2010).

Prevenir acidentes decorrentes dessa exposição é um dos principais interesses a serem sanados, devido ao fato de que muitos deles poderiam ser evitados, se houvesse um melhor sistema de educação relacionado à segurança pessoal e do ambiente, visto que a maioria ocorre por falha humana (MULLER; MASTROENI, 2004).

Os profissionais que atuam na área de análises clínicas estão constantemente expostos a riscos, dentre eles, os ergonômicos, físicos, químicos, biológicos e de acidentes. Esses profissionais devem estar cientes dos riscos e de como preveni-los e, se ainda assim um acidente ocorrer, o profissional tem de estar consciente de como tomar a conduta adequada (ZOCHIO, 2009).

Esses riscos são denominados riscos ocupacionais. O risco ergonômico é definido como qualquer coisa que afete a saúde psicofisiológica do profissional. Os riscos físicos são as formas de energia que o profissional possa estar exposto, tais como: vibrações, ruído, calor, entre outros. O risco químico é definido como as substâncias compostas ou produtos que possam penetrar no organismo pela via respiratória ou por ingestão, como, por exemplo, poeiras e gases. 0 risco de acidentes é qualquer fator que coloque o trabalhador em situação de perigo e possa afetar sua integridade, bem-estar físico e moral, como, por exemplo, a falta de manutenção das máquinas e armazenamentos inadequados. E, por último, os riscos biológicos, que são as bactérias, fungos, parasitos, vírus, entre outros (FIALHO; MATOS, 2010).

Os riscos biológicos podem ser subdivididos em 4 classes, que são definidas por grau de risco. Para determinar esses riscos são avaliados alguns critérios como a patogenicidade, virulência, modos de transmissão, disponibilidade de medidas profiláticas, disponibilidade de tratamento eficaz e endemicidade.

$\mathrm{Na}$ classe de risco 1, o risco é baixo para o indivíduo e nulo para a comunidade. São agentes biológicos que não apresentam ou apresentam baixa patogenicidade para o homem e para os animais sadios. Na classe de risco 2, o risco é moderado para o indivíduo e baixo para a comunidade. São agentes biológicos que provocam infecções no homem ou nos animais, porém com baixa ou nula propagação ao ambiente. Na classe de risco 3, o risco individual é alto e para comunidade é moderado. São agentes biológicos que provocam infecções, graves ou letais no homem e nos animais e representam um sério risco a quem os manipulam. Apresenta também risco para a comunidade e meio ambiente, podendo se disseminar de indivíduo para indivíduo. E, por último, na classe de risco 4, tanto o risco individual e quanto o risco para a comunidade são altos. São agentes biológicos de fácil propagação, altamente patogênicos para o homem, animais e meio ambiente, representando grande risco a quem os manipula (BERNARDINO; PAIZANTE, 2008).

No Brasil, os dados sobre os acidentes relacionados à biossegurança entre os profissionais que trabalham em laboratórios ou na área da saúde demonstram que a maior parte dos acidentes resultantes em infecções é entre os estudantes universitários, que desempenham o papel de estagiários 
nesses ambientes de trabalho. Logo depois dos estudantes universitários se encontram os técnicos de laboratório e os serventes. Tudo isso se deve à falta de conhecimentos necessários da biossegurança (MACIEL et al., 2005).

Esses dados poderiam ser modificados se fosse introduzido o ensino da biossegurança desde o início da formação profissional. Uma das principais preocupações da sociedade e que deve ser considerada prioridade é a educação. É por meio do sistema de educação que uma pessoa se torna capacitada para a atuação profissional, além da formação do indivíduo, do ensino e da aprendizagem (SILVA; OLIVEIRA; BOLFE, 2013).

Geralmente, as metodologias de ensino são pouco atrativas, ultrapassadas e não estimulam a visão crítica. Sendo assim, os alunos acabam se tornando cada vez mais passivos, desinteressados e dependentes do seu educador para o seu aprendizado individual. Nota-se, então, a necessidade de metodologias de ensino que sejam estimulantes e se adequem à modernidade do século em que vivemos. Por isso os métodos de ensino estão passando por diversas mudanças, em especial pela falta de tempo em que as pessoas se encontram, além da necessidade que muitos estudantes enfrentam de múltiplas jornadas, como, por exemplo, a saída do trabalho e a ida para faculdade (BRUCE-LOW et al, 2013).

A metodologia proposta pelo psicopedagogo David Ausubel se encaixa nessa necessidade, tendo como princípio fundamental o conjunto de conhecimentos que o aluno já possui. Esse princípio é denominado de estrutura cognitiva que, segundo ele, é a variável mais importante que o educando deve levar em consideração. Dentro dessa estrutura cognitiva, está a aprendizagem significativa, para a qual existe a necessidade de se estabelecer uma relação paralela sobre o conhecimento já existente do aluno, com o novo conhecimento a ser aprendido, podendo ser uma figura, uma teoria ou uma proposição (PELIZZARI et al., 2012).

Seguindo a teoria de aprendizagem significativa, optou-se, neste trabalho, pela criação de um jogo educativo com a temática: biossegurança nos laboratórios de Análises Clínicas.

Antigamente, os jogos já eram utilizados como metodologia de ensino, porém ainda existia uma grande barreira de aceitação em relação a eles, que eram vistos de forma negativa, como meio de lazer, quando utilizados na educação. Hoje, os jogos educativos são mais utilizados, fomentam a aprendizagem e são aceitos como estratégia didática nos Parâmetros Curriculares Nacionais. Acredita-se que por meio deles o aprendizado se torna menos monótono, estimulando a curiosidade por determinado assunto, 0 autoconhecimento e a criatividade, de modo menos cansativo e mais prazeroso. Eles têm vantagens significativas, quando utilizados para o ensino, como o desenvolvimento de raciocínio crítico, possibilitando a criação de suposições e habilidades para a resolução das adversidades (CONTIN; FERREIRA, 2008).

Com os avanços tecnológicos, a disseminação da informação tem tomado ampla distribuição, sem contar na rapidez com que isso ocorre. Em decorrência disso, os educadores se veem cada vez mais necessitados de métodos de ensino mais atuais, que utilizem ferramentas inovadoras e motivacionais para esse alcance. Devido a isso, os docentes têm buscado recorrer a instrumentos pedagógicos aplicáveis com a intenção de estimular cada vez mais os alunos a quererem aprender (FIALHO; MATOS, 2010).

Em função disso, ressalta-se a importância de metodologias que prezem por estimular à autoaprendizagem, por métodos interativos que incentivem o conhecimento, o senso crítico, a análise das situações que o forcem o aluno a tomar decisões sobre como agir em determinada situação e a resolver problemas (LONGMUIR, 2014). 
Além disso, as metodologias não afetam apenas os alunos, mas também os profissionais do ensino que necessitam de novos recursos para transferirem seu conhecimento, de modo que não se tornem exaustivos e desinteressantes. Reforça-se, então, a necessidade da criação de novos mecanismos que auxiliem aos educandos e aos professores a continuarem a ensinar e aprender. (SILVA; OLIVEIRA; BOLFE, 2013).

Devido a essa necessidade, surgiu a tecnologia chamada de Mobile Learning, uma mobilidade que permite o ensino a distância, que, além de oferecer o aprendizado, é dinâmico e interativo e funcional na comunicação móvel, utilizando redes sem fio; serviços de mensagens curtas, mais conhecidos como SMS; e-mails; possibilidade de transferência de conteúdo, entre outros, fazendo uso do celular (CERI; FRATERNALI; BONGIO, 2013).

Essa nova metodologia fez com que até mesmo os computadores tivessem que se adaptar à nova necessidade do século. As telas se tornaram cada vez menores e o acesso chegou às telas de celulares, de modo a facilitar que qualquer pessoa, em qualquer lugar, pudesse obter as informações desejadas (BRUCE-LOW et al, 2013). A popularização do uso de celulares no mundo atual é visível. Mais da metade da população possui um aparelho e essa popularização vem despertando o interesse das empresas de criação, como também dos discentes, para o uso de forma educativa desse dispositivo. 0 m-learning, então, é esse ramo de pesquisa que tem como função averiguar de que forma esses aparelhos podem contribuir para o ensino e aprendizagem (ROBLES; GONZÁLEZ-BARAHONA; FERNÁNDEZ-GONZÁLEZ, 2011).

O presente trabalho teve como objetivo a construção de um jogo como um instrumento pedagógico para o ensino e a conscientização da importância da biossegurança nos laboratórios de Análises Clínicas.

\section{CAMINHO METOdOLÓGICO}

O início do presente trabalho deu-se pelo entendimento dos principais motivos a se criar um método interativo de ensino, relacionado à biossegurança, com base na literatura sobre as principais falhas e necessidades na área de Análises Clínicas e sobre novos métodos de ensino empregados atualmente. Nessa perspectiva, foi sugerido o uso da tecnologia voltada para celulares de forma acessível em qualquer lugar. Devido a isso, optou-se pela aprendizagem móvel. Foi criado um jogo com o objetivo de prevenção ou minimização dos riscos referentes à biossegurança, com base de ensino sobre como funciona um laboratório de análises clínicas. 0 público-alvo dessa ferramenta de ensino são os estudantes de áreas da saúde e profissionais atuantes na área de Análises Clínicas.

\subsection{A elaboração do jogo}

O jogo foi concebido no estilo "aventura", e sua jogabilidade em jogos Point-and-click, no português Apontar-e-Clicar.

O estilo "aventura" define jogos em que o jogador assume o papel de um protagonista em uma história interativa com exploração e resolução de quebra-cabeças.

A jogabilidade, denominada Point-and-click, se baseia no ato de apontar o cursor (ponteiro) nesse caso o próprio dedo, por se tratar de jogo para dispositivos móveis com tela sensível ao toque - sobre um objeto e clicar, a fim de o selecionar e/ou desencadear sequência de ações baseadas no contexto ao que tal objeto se encontra empregado. 
Tais definições, quanto ao estilo e jogabilidade aplicadas, foram tomadas por empregarem contextos dinâmicos e interativos, permitindo que o conteúdo seja mais bem compreendido e menos exaustivo, visando ao aprendizado de maneira divertida, ou seja, "aprender brincando". Assim, surge o conceito do jogo dinâmico e educativo.

O jogo foi produzido, utilizando-se aplicativos profissionais, cada qual com determinada função, tendo ou não a inclusão de Módulos adicionais, adicionando funcionalidades ao aplicativo, a fim de facilitar a execução e/ou aprimorar o trabalho final. Tais aplicativos estão listados abaixo.

- Unity 3D - versão 4.6

- Aplicativo para criação de jogos (gratuito). Fornece o Motor do jogo (Game Engine);

- MonoDevelop - Editor de códigos integrado;

- Adventure Creator - Módulo adicional que fornece funcionalidades específicas para criação de jogos de aventura, como criação simplificada de interações, diálogos e menus.

- $\quad$ Adobe Illustrator - versão CS6

- Aplicativo responsável por criação de arte digital, como cenários, personagens e objetos.

- Photoshop - versão CS6

- Aplicativo para pintura e edição de arte digital.

Motor de Jogo é um conjunto de bibliotecas para simplificar e abstrair o desenvolvimento de jogos eletrônicos ou outras aplicações com gráficos em tempo real, para videogames e/ou computadores, rodando sistemas operacionais. A funcionalidade fornecida por um motor de jogo inclui: um motor gráfico para renderizar (ato de compilar e obter o produto final de um processamento digital) gráficos 2D e/ou 3D; um motor de física para simular a física ou fazer detecção de colisão; suporte à animação, sons, inteligência artificial; uso de comunicação de rede; gerência de memória; gerência de arquivos; gerência de linha de execução; suporte a grafos de cena e entidades, além de suporte a uma linguagem de script.

\subsubsection{Desenvolvimento do jogo}

O Desenvolvimento do jogo foi realizado, utilizando-se o aplicativo Unity $3 D$, que será referenciado somente como Unity.

Um fluxo de trabalho foi previamente definido, sendo que, no momento do desenvolvimento, as imagens e texturas, como o personagem principal, cenários e objetos, já haviam sido desenhados e editados.

Utilizando-se o Unity, cada um dos ambientes foi definido como uma nova cena e, em cada cena, foram definidas as propriedades, como dimensões, pontos de colisão e área transitável. Foi também definido o posicionamento das câmeras presentes no jogo e as animações realizadas pelo personagem principal (Figura 1). 
Figura 1 - A animação da movimentação do personagem.

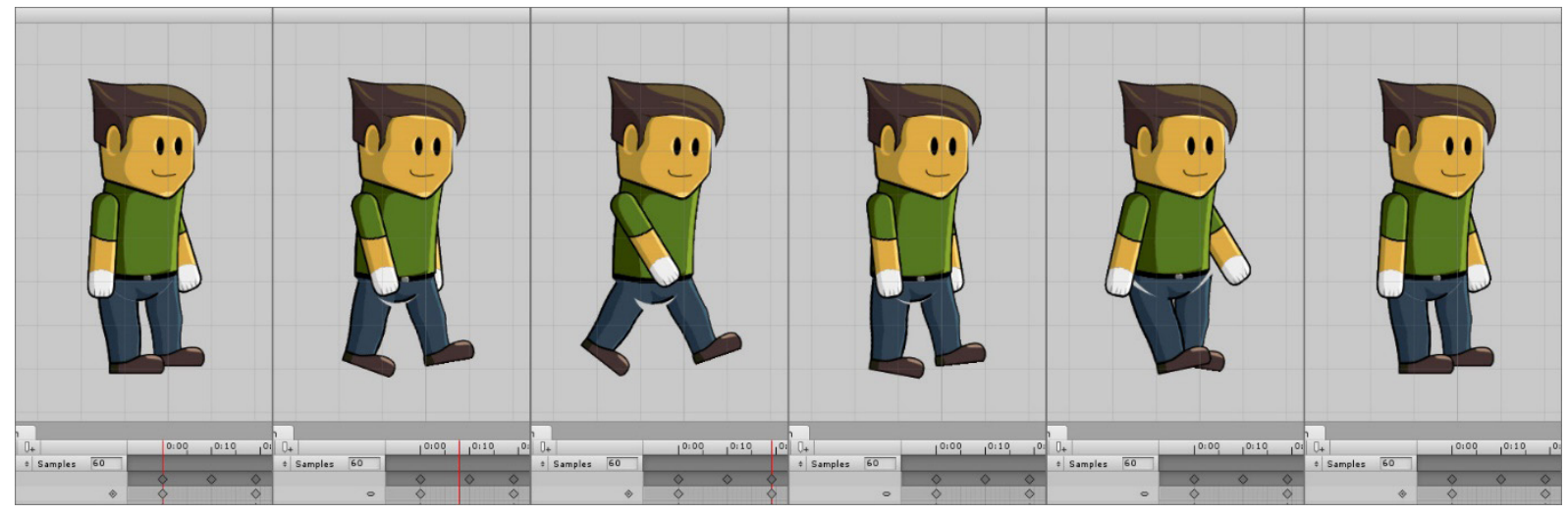

Fonte: Os Autores.

Além disso, em cada cena, foram posicionados os objetos interativos, assim como foram definidas suas interações, vinculando-as às ações do personagem.

\subsubsection{A ELABORAÇÃO DO PERSONAGEM}

A elaboração do personagem foi realizada, utilizando-se o aplicativo Adobe Illustrator CS6 (Figura 2), consistindo-se apenas na versão masculina. 0 personagem é baseado na forma cartunista, não sendo realista nos traços corporais, na conotação sexual ou nas articulações dos movimentos. É constituído por cabelo no comprimento padrão utilizado para identificação masculina, cabeça (olhos e boca), tronco, membros e pés, trajando calça, camisa e sapatos.

Figura 2 - Produção da versão Alpha do personagem na forma masculina, utilizando o Adobe Illustrator CS6

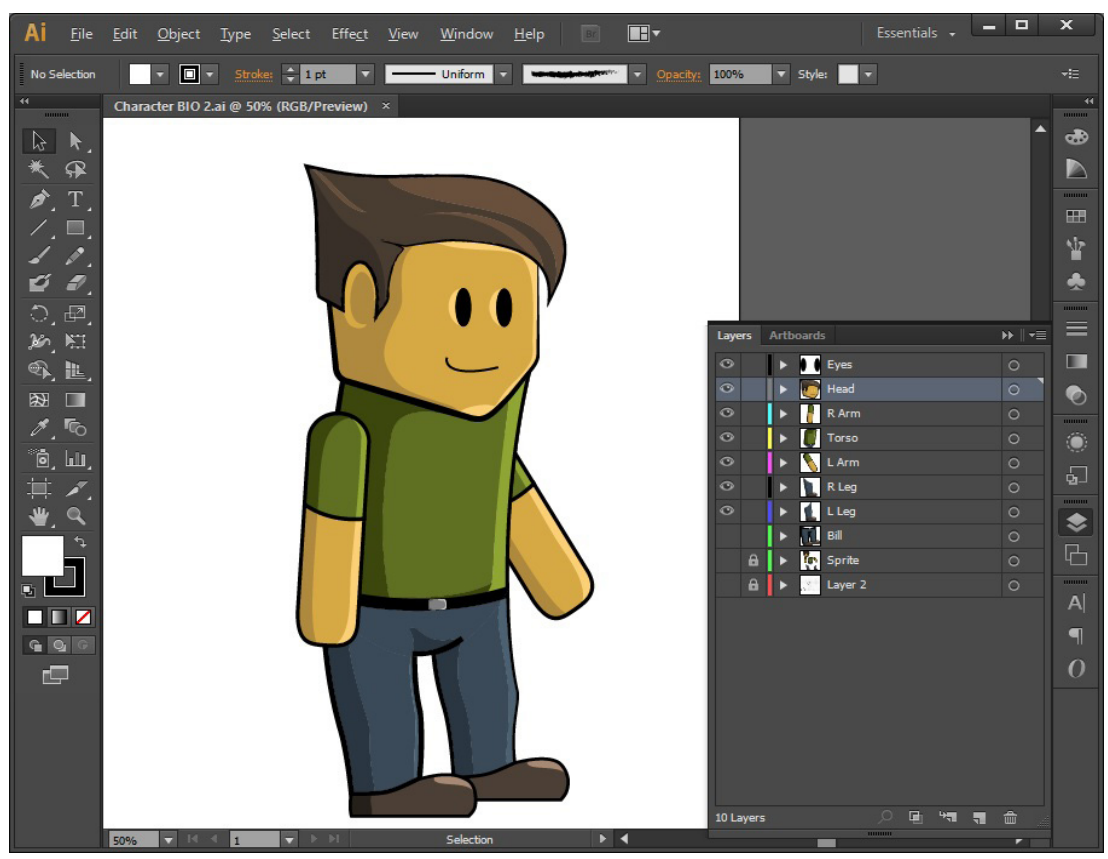

Fonte: Os Autores. 


\subsubsection{A elaboração do cenário}

O projeto do jogo tem como foco a elaboração dos cenários (Figura 3), objetos e texturas, além das interfaces gráficas e funcionamento. Foi criado um laboratório, local de trabalho do profissional de análises clínicas, dividido em 8 salas de acordo com os possíveis setores de atuação. 0 jogo consiste na planta de oito cômodos, na seguinte sequência: recepção, sala de coleta, setor de Hematologia, setor de Bioquímica, setor de Imunologia, setor de Urinálise, setor de Parasitologia e, por último, setor de Microbiologia. Foram utilizados os programas Unity 3D - versão 4.6 (Figura 4) e o Adobe Illustrator CS6.

Figura 3 - Processo de produção do cenário.

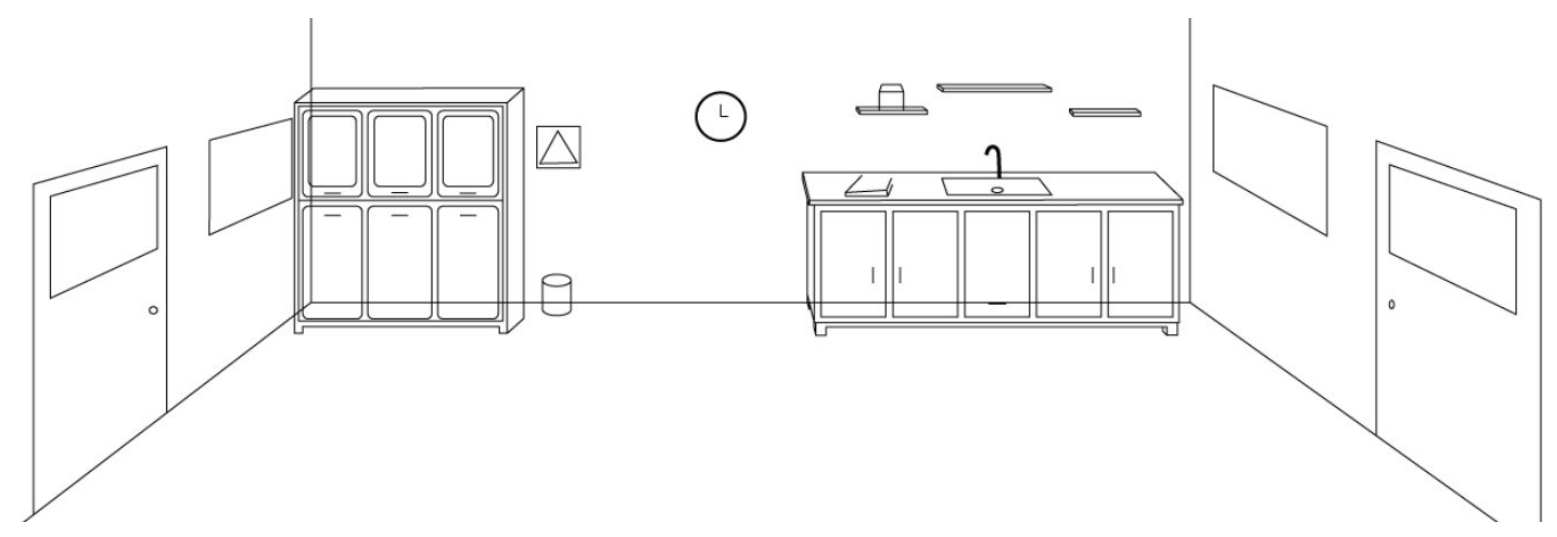

Fonte: Os Autores. 
Figura 4 - Produção da versão Alpha do plano de fundo e representação gráfica do jogo, utilizando-se o Unity 3D.

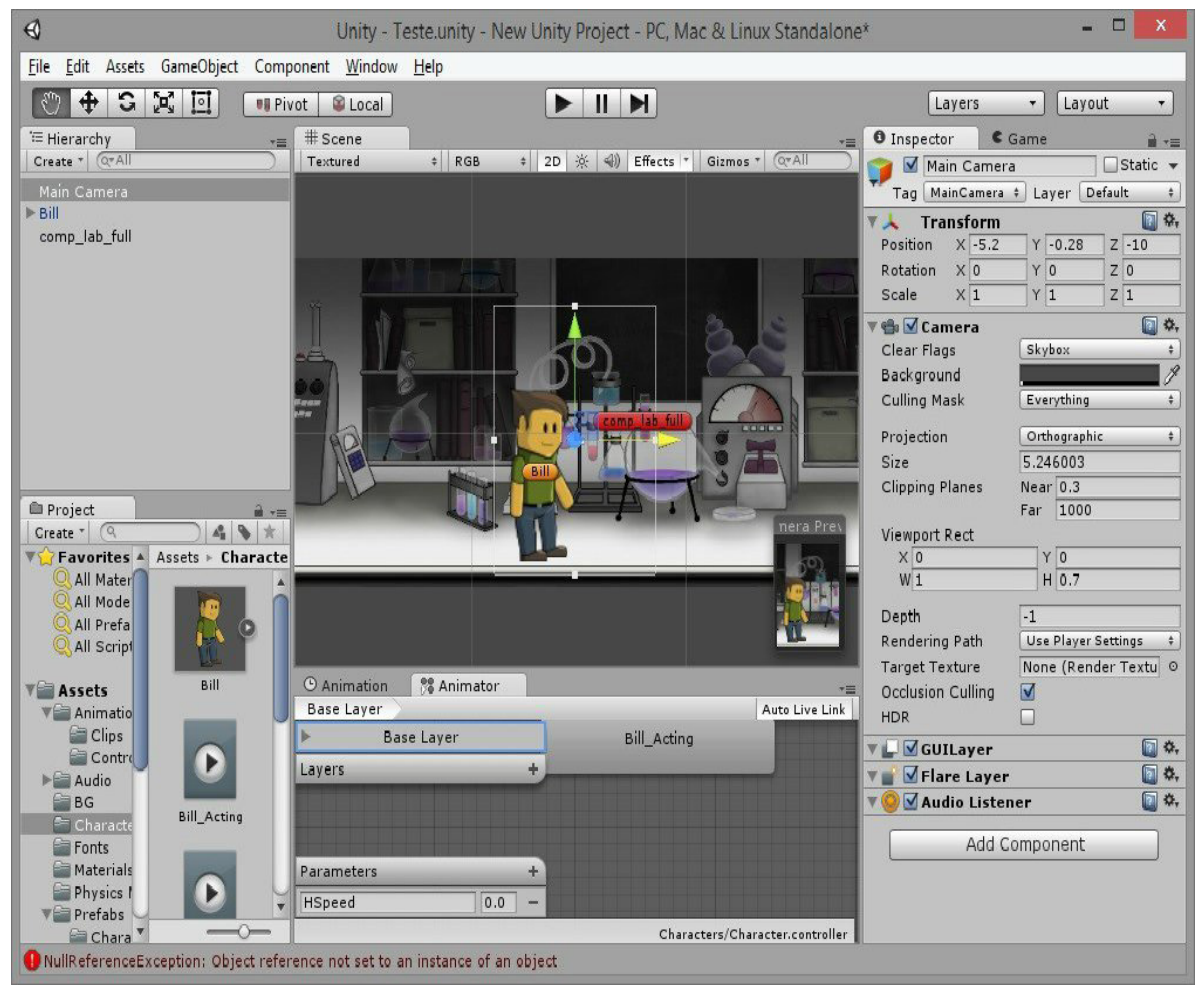

Fonte: Os Autores.

\subsubsection{Elaboração da dinâmica}

Foi realizada a criação das adversidades que serão enfrentadas no jogo, com base nas normas de biossegurança, de forma lúdica. 0 jogo tem início na recepção, passando por todas as demais salas constituintes, sendo que, em cada uma delas, existirá um determinado nível de dificuldade, como, por exemplo: acertar quais os equipamentos de proteção individual devem ser utilizados na determinada sala, onde descartar determinados objetos de utilização no laboratório, entre outros.

Além das adversidades existentes no jogo, o jogador enfrentará outros tipos de dificuldades, como perguntas sobre biossegurança de acordo com a sala em que está, como os tipos de riscos existentes dentro da biossegurança: biológicos, químicos, físicos, ergonômicos e de acidentes.

No final de cada desafio realizado, as respostas aparecerão, para que o jogador tome ciência de qual deveria ser a resposta correta, aprendendo com os erros e acertos obtidos. E, ao final de cada adversidade encontrada de acordo com as respectivas salas, ele aprende as condutas corretas a se tomar em um ambiente laboratorial, tornando assim o jogo um método de ensino sem perder a diversão, que é o intuito principal de um jogo.

As instruções do jogo estarão disponíveis em português (brasileiro), língua oficial do país, explicando o procedimento e a sequência das salas. Se as normas de biossegurança da área não forem respeitadas, é explicado o motivo do erro e ocorre o fim do jogo, fazendo com que o jogador retorne a sala inicial, no caso, a recepção. Caso contrário, acertando o desafio ou a questão proposta, o personagem segue para a sala adiante. Se tudo for feito de acordo as normas de biossegurança, o jogador passará por todas as salas, chegando ao final do expediente de trabalho, vencendo o jogo. 


\subsubsection{Disponibilização do jogo}

O jogo será disponibilizado para plataforma Android e poderá ser acessado gratuitamente para download, com o nome de MyBioGame.apk, por meio dos seguintes métodos:

- Repositório online OneDrive

- Link: http://1drv.ms/1iW9Ct1

- Código QR

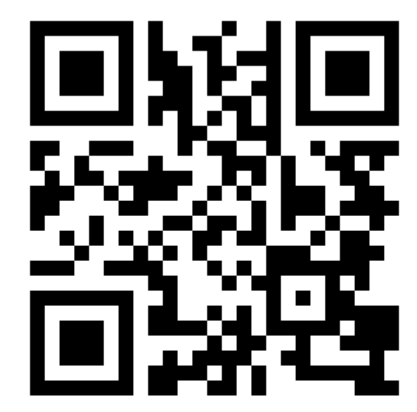

Sugerimos download diretamente, via dispositivo móvel com sistema Android.

Será necessário autorização para instalação do aplicativo no sistema, seguindo os procedimentos listados abaixo:

- Acesse o menu e escolher a área das "Configurações" (Settings);

- Abra a alternativa "Segurança" (Security);

- Nesse submenu, marque a opção "Fontes Desconhecidas" (Unknown Sources).

Após download desse arquivo e configuração do dispositivo, execute-o. Será questionada a intenção de se instalar tal aplicativo, que deve ser confirmada.

\section{ANÁLISE E DISCUSSÃO}

Um dos principais problemas enfrentados pelos educadores, hoje, é o de conseguir manter os alunos interessados e concentrados, principalmente pelo fato de a tecnologia estar cada vez mais presente na vida dos seres humanos. Cabe aos professores usufruir dessa tecnologia, utilizando-a como ferramenta de apoio ao processo ensino-aprendizagem, tornando o aprendizado dinâmico e estimulante (FELDER et al, 2013).

O MyBio Game surge, então, na ânsia de possibilitar a vivência do conteúdo teórico de forma prática, através de um universo virtual, de forma educativa e divertida. 0 conceito trabalhado no jogo é baseado em fatos que possam vir a ocorrer dentro do ambiente de trabalho de profissionais da área de saúde. Um dos grandes propósitos do jogo é discutir os conteúdos de biossegurança, utilizandose as potencialidades do mobile learning, já que a interatividade é um dos principais motivos que leva 
as pessoas a utilizarem das tecnologias móveis e de que a fixação do conhecimento seja melhorada através da prática (BRUCE-LOW et al, 2013).

Baseado em Fialho e Matos (2010), diante dessa nova realidade em que vivemos, na qual a tecnologia está constantemente presente, cabe aos professores inserirem novos recursos pedagógicos aplicáveis, no intuito de despertar a curiosidade e o interesse por parte dos alunos. Nessa perspectiva, destacam-se as metodologias ativas que estimulam a autoaprendizagem e reforçam os conhecimentos adquiridos pelo aluno, que é o ponto de partida da teoria de David Ausubel.

Martinez, Fujihara e Martins (2008) acreditam que informações de difícil assimilação precisam de métodos que auxiliem no aprendizado dos alunos. Por isso, métodos inovadores de ensino vêm surgindo e trazendo resultados promissores, como os jogos lúdicos tecnológicos que auxiliam muito no processo aprendizagem, complementando o conteúdo teórico e permitindo uma maior interação do aluno com a matéria ensinada.

Para Contin e Ferreira (2008), os jogos são importantes ferramentas auxiliares na educação nas mais diversas áreas do conhecimento e, por serem divertidos e prazerosos, tornam o ensino muito mais eficaz, sendo assim uma ótima estratégia para melhorar o desempenho dos alunos.

O jogo MyBio Game é uma ferramenta complementar, pois é importante o ensino prévio dos conteúdos pelo professor. Não é aconselhado que seja aplicado para outro público além do citado, visto que, apesar das interfaces gráficas serem atrativas ao público infantil e infanto-juvenil, o conteúdo não é apropriado. O MyBio Game apresenta de forma dinâmica os funcionamentos de um laboratório de análises clínicas e ensina como agir de forma correta dentro desse ambiente..

\section{CONSIDERAÇÕES FINAIS}

Muitos casos de acidentes laboratoriais poderiam ser evitados, se houvesse um melhor sistema de educação voltado à biossegurança. Por isso, ressalta-se a importância da necessidade de que existam mais iniciativas e estudos de elaboração de produtos educativos para o auxílio na fixação do conhecimento. Nesse sentido, acredita-se que a implantação do jogo MyBio Game poderá contribuir para a aprendizagem significativa, estimular a memória, a atenção e a criatividade. Acredita-se que o jogo possa motivar o aluno e despertar o interesse e a curiosidade, além de gerar uma reflexão sobre as atitudes tomadas dentro do seu local e/ou futuro local de trabalho, gerando benefícios, tanto para o meio escolar como para o profissional, visto que o conhecimento das normas de biossegurança minimizaria os riscos de acidentes.

Dessa forma, entende-se que a educação é primordial para a vida pessoal e profissional de um indivíduo e que as novas estratégias educativas são fundamentais no processo de ensino-aprendizagem, tendo efeitos positivos nos quesitos de motivação, curiosidade e interesse no aprendizado. Cabem aos educadores saberem aproveitar essas novas metodologias para que os alunos internalizem e coloquem em prática esses ensinamentos. 
Suzana Angélica Silva Lustosa / Márcia Dorcelina Trindade Cardoso Gabriel Vassalo de Souza I Ana Paula Campos de Souza I Alice Juliana Otoni Muller Santos

\section{REFERÊNCIAS}

ANDRADE, L. Z. C.; FREITAS, D. T.; HOLANDA, G. F.; SILVA, V. M.; LOPES, M. V. O.; ARAÚJO, T. L. Desenvolvimento e validação de jogo educativo: medida da pressão arterial. Rev Enferm, v.20, n.3, p. $323-327,2012$.

BERNARDINO, S. R. H.; PAIZANTE, G. O. "Análise dos Registros de Acidentes Ocupacionais, Ocasionados por Perfurocortantes". Revista Meio Ambiente e Saúde, v. 2, p. 136-15, 2008.

BRUCE-LOW, S. S.; BURNET, S.; ARBER, K.; PRICE, D.; WEBSTER, L.; STOPFORTH, M. Interactive mobile learning: a pilot study of a new approach for sport science and medical undergraduate students. Adv Physiol Educ, v. 37, 2013.

CERI, S.; FRATERNALI, P.; BONGIO, A. “Web Modeling Language (WebML): a Modeling Language for Designing Web Sites". Disponível em: <http://webml.org/webml/upload/ent5/1/www9.pdf $>$. Acesso em: 11 set. 2014.

COMISSÃO TÉCNICA NACIONAL DE BIOSSEGURANÇA - CTNBio. Disponível em: <http://www.ctnbio. gov.br/ctnbio/default.htm>. Acesso em: 03 out. 2015.

CONTIN, R. C.; FERREIRA, W. A. Jogos: Instrumentos pedagógicos no Ensino da Matemática. Disponível em: <http://www.portaldaeducacao.seduc.mt.gov.br/cefaprocaceres $>$. Acesso em: 11 set. 2014.

FIALHO, N. N.; MATOS, E. L. M. A arte de envolver o aluno na aprendizagem de ciências utilizando softwares educacionais. Educação em Revista, 2010.

LONGMUIR K. J. Interactive computer-assisted instruction in acid-base physiology for mobile computer platforms. Adv Physiol Educ, v. 38, 2014.

MACIEL, E. L. N.; VIANA, M. C.; ZEITONE, R. C. G.; FERREIRA, I.; FREGONA, G.; DIETZE, R. Prevalence and incidence of Mycobacterium tuberculosis infection innursing students in Vitória, Espírito Santo. Revista da Sociedade Brasileira de Medicina Tropical, v.38, n. 6, 2005.

MAMEDE, S.; PENAFORTE, J. Aprendizagem baseada em problemas: anatomia de uma nova abordagem educacional, Hucitec, p.49 - 78, 2001.

MARTINEZ, E. R. M.; FUJIHARA, R. T.; MARTINS, C. Show da Genética: um jogo interativo para o ensino de genética. Disponível em: <http://www.educadores.diaadia.pr.gov.br/arquivos/File/2010/artigos_teses/ Biologia/Artigos/showgene.pdf>. Acesso em: 14 ago. 2015.

MÜLLER I. C.; MASTROENI M. F. Tendência de acidentes em laboratórios de pesquisa. Revista Biotecnologia Ciência \& Desenvolvimento, n. 33, 2004.

PELIZZARI, A.; KRIEGL, M. L.; BARON, M. P.; FINCK, N. T. L. DOROCINSKI, S. I. Teoria da aprendizagem significativa segundo Ausubel. Revista Psicologia, Educação e Cultura, v.2, n. 1, p.37-42, 2002.

ROBLES, G.; GONZÁLEZ-BARAHONA, J. M.; FERNÁNDEZ-GONZÁLEZ, J. Implementing Gymkhanas with Android smartphones: A multimedia m-learning game. Proceedings of the IEEE Global Engineering Education Conference (EDUCON), 2010. 
SILVA, A. D. R. L.; MASTROENI, M. F. Biossegurança: O conhecimento dos formatos da área da saúde. Revista Baiana de saúde pública, v. 33, n. 3, p. 476 - 487, 2010.

SILVA, L. F.; OLIVEIRA, E. D., BOLFE, M. Mobile Learning Aprendizagem com mobilidade. Colloquium Exactarum, v. 5, p. 59 - 65, 2013.

ZOCHIO, L. B. Biossegurança em Laboratórios de Análises Clínicas. Disponível em: <http://www. ciencianews.com.br/arquivos/ACET/IMAGENS/revista_virtual/administracao_laboratorial/trabzochio. pdf >. Acesso em: 06 abr. 2015.

FELDER, E.; FAULER, M.; GEILER, S. Introducing e-learning/teaching in a physiology course for medical students: acceptance by students and subjective effect on learning. Advances in Physiology Education, v. 37, n. $4,2013$. 